\title{
DE PERSONAS Y DE TERRITORIOS. LA DEFENSA DEL REINO DE MURCIA ENTRE LOS SIGLOS XVI Y LA PRIMERA MITAD DEL SIGLO XVIII
}

\author{
Julio D. Muñoz Rodríguez \& José Javier Ruiz Ibáñez \\ Universidad de Murcia
}

\begin{abstract}
Resumen. Espacio poco poblado y marginal en la edad media, el reino de Murcia alcanzó un mayor protagonismo gracias a la relativa pacificación general que trajo la política de los Reyes Católicos. Teniendo que defender un amplio espacio costero de las agresiones corsarias, los territorios que lo integraban se definieron por las demandas que se les hacían para contribuir a la defensa. Así pues, el tipo de amenazas, su origen, su frecuencia y la respuesta que se les dieron fueron decisivos para hacer evolucionar el significado mismo del reino y sus formas de integración en la monarquía. Esto fue tanto por lo que respecta al innegable crecimiento del poder ejercido en nombre del servicio directo al rey, como por la pervivencia de las capacidades de defensa de las instituciones locales.
\end{abstract}

Palabras clave: Guerra, memoria, jurisdicción, defensa, siglos XVI-XVIII

Abstract. The kingdom of Murcia, a sparsely populated space and quite marginal during the Middle Ages, got a certain prominence due to the general pacification led by the Catholic Monarchs. These territories defined themselves by the importance of their situation: valued as a strategic position to defend the coast from the aggressions of corsairs, this type of menace, its origin, frequency and response greatly influenced the definition and the integration of the kingdom into the Monarchy. Considered a direct service to the king, its power also increased due to the persistence of the defensive capacities of the local institutions.

Keywords: War, memory, jurisdiction, defense, $16^{\text {th }}-18^{\text {th }}$ centuries

Recibido: 9-11-2020 . Aceptado: 2-05-2021 .jjruiz@um.es 


\section{El recuerdo de la defensa}

El ANÁlisis EN UN TIEMPo LARGo DE UN TERRITORIO, en este caso el reino de Murcia, permite comprender los mecanismos que articulaban la defensa dentro de una monarquía politerritorial como la Hispánica. Las singularidades locales sólo pueden cobrar sentido en una comprensión de conjunto que las sitúen en un marco mucho mayor. Así pues, el estudio concreto debe adoptar una perspectiva binaria: por lado su inserción en una historia compleja de la monarquía que explique muchos de los fenómenos y las cronologías que se detectan y que nada tienen de esenciales o propias, pero, por otro, ese estudio denso muestra hasta qué punto las ideas generales defendidas sobre la organización militar hispana permiten comprender la realidad subyacente o deben ser matizadas. Frontera activa durante tres siglos, lejos de los núcleos de poder cortesanos, el reino de Murcia ofrece una ilustración clara de cómo la sociedad y poder imperial confrontaban la proyección de la Monarquía Hispánica, definiendo unas líneas que pueden ser identificadas en otros ámbitos.

Hacia finales del siglo XVII el cabildo de la ciudad de Murcia hacía recuento de sus más destacadas acciones en defensa de la monarquía. No se trataba, como se había realizado en otras ocasiones, de recordar los servicios económicos directos o la concesión de millones que, en nombre del reino o en el suyo propio, había hecho el ayuntamiento murciano y que sus regidores estarían muy atentos de sumar a sus méritos cada vez que demandaran una merced regia. En esta ocasión se buscaba recapitular las veces, al menos las más señaladas, que las fuerzas urbanas habían tomado el arcabuz o el mosquete y habían corrido a socorrer las fronteras de la monarquía. Dentro de esa memoria incompleta e interesada, como lo son todas las memorias, la ciudad acumulaba información sobre algunos de los altos hechos de sus hombres: el socorro general a la costa de mayo y junio de 1643, el que se envió ese mismo 1643 a Orán seleccionando soldados de entre las compañías de las parroquias y señalando a sus familias una compensación semanal de 12 reales, la gran movilización que se realizó en enero de 1656 cuando se levantaron seis compañías de parroquias y las dos de la milicia general, la de 1675 en la que, siempre según la ciudad, se despacharon dos mil hombres a Cartagena y quinientos a Orán (lo que incluía tres compañías parroquiales y dos de milicia general) quienes permanecieron dos años, «sacrificando muchos sus vidas en servicio de su majestad y todos su caudal y Hazienda», los quinientos hombres del socorro enviado en 1682, las dos compañías con doscientos treinta hombres despachados en 1691 y los quinientos en cinco compañías remitidos en 1693 para reforzar, como en el caso anterior, Cartagena ${ }^{1}$.

1 El memorial aparece recogido en Archivo Municipal de Murcia (en adelante AMM), leg. 2.753, sin número. 
Esta recopilación de méritos colectivos e individuales, de dedicación al servicio del rey y a la defensa de los reinos y la tierra, no era algo excepcional de la capital del reino de Murcia. Las diversas localidades del reino, tanto las de la costa como las del interior, tenían muy presente su empeño en el servicio real en su historia reciente y no dejaban de argumentar el sacrificio que éste conllevaba para justificar las peticiones para que, en su caso al menos, se moderaran las demandas fiscales de los reyes.

Desde principios del siglo XVII se había hecho un esfuerzo creciente por gestionar mejor un pasado que servía como argumento para defender el honor colectivo, los privilegios de las poblaciones y los méritos de sus poderosos. No sólo era la política de apoyo editorial a las corografías locales, sino también una mejor gestión de los archivos municipales, algo que, por lo demás, se hacía cada vez más urgente ante las demandas regias, los crecientes pleitos de jurisdicción o las reclamaciones de impagos (Centenero de Arce, 2011, pp. 92-104; Guillamón Álvarez y Ruiz Ibáñez, 1999, pp. 486-487).

La terrible crisis que asoló el reino entre 1630 y 1656 detuvo esta producción de memoria, aunque no completamente, como evidencia el interés del ayuntamiento de Murcia por localizar sus papeles una vez que la terrible riada de San Calixto (1651) anegó las casas municipales. La inversión en una memoria heroica y sufriente se había vuelto urgente con el fin de contar con argumentos solventes frente a la insistencia regia de que el reino entregara más hombres y más dinero. Esta construcción del pasado se materializaba en las súplicas, memoriales y correspondencias que la ciudad y sus representantes en la corte mandaban al soberano que, además de probar su participación en el servicio colectivo urbano, incidían en la imposibilidad de dar más recursos y en la inoportunidad de pedirlos por parte de los agentes de rey (Ruiz Ibáñez, 2004, pp. 667-670).

Todo este discurso tendría un futuro limitado y pronto quedaría sepultada por los acontecimientos que se desarrollaron en el reino durante la Guerra de Sucesión, uno de los escenarios principales en el espacio peninsular. Las dos invasiones del reino por las fuerzas agresoras austracistas en 1706 y 1707, así como la contraofensiva borbónica sobre el reino de Valencia, fueron ocasión para que viejas lealtades y nuevas fidelidades se afirmaran en una situación de extrema emergencia. Superada la crisis de 1706, consolidado el poder borbónico y salvada la autonomía municipal, los particulares y las corporaciones urbanas se apresuraron a solicitar el reconocimiento real. Felipe V no fue parco en otorgar su merced a tales vasallos y los timbres honoríficos dispensados por el soberano pasaron a adornar apellidos y blasones. Los beneficios de la merced borbónica, una gracia, por lo demás ganada con la espada en la mano, no sólo recayeron en personas concretas, sino que también repercutían en el honor colectivo al afectar al conjunto de la población urbana y expresarse en sus 
armerías (Muñoz Rodríguez, 2014, pp. 293-313). La honra recibida situaba en ese momento fundacional, en ese tiempo visto ahora como heroico, la referencia memorial necesaria para justificar los estatutos adquiridos o para inventarlos. Frente al éxito de la participación murciana en la Guerra de Sucesión, las acciones previas no sólo parecían mezquinas, sino que remitían a una acción colectiva en la que habían participado todos, tanto quienes tomaron partido por el archiduque Carlos como quienes permanecieron leales al rey y a la república urbana, detalle de gran importancia que ahora parecía menos urgente recordar.

La propia memoria de la Guerra de Sucesión, vista como un momento extraordinario, ayudó a borrar o, al menos, a minimizar del recuerdo colectivo las empresas anteriores, más aún cuando la intensidad de los ataques a la costa y la profesionalización de la defensa, salvo ocasiones de alarma cada vez más puntuales, ayudaron a debilitar la necesidad de una movilización urbana para protegerse de las amenazas llegadas desde el mar y salvaguardar la posición hispana en Orán, esta última restablecida en 1732 tras su pérdida en 1708. Poco a poco el recuerdo de la participación armada de las ciudades y villas del reino de Murcia en la defensa directa de la monarquía quedó relegada a una serie de lugares comunes que incidía en una difusa peligrosidad costera, o que, como sucedería con la villa de Almazarrón, estaría ligada a una festividad religiosa que funcionaría como productora de identidad local (García Moreno, 2014; Velasco Hernández, 2014).

La peligrosidad del litoral y sus socorros, sin embargo, habían definido el carácter del reino entre los siglos XV y XVIII, un carácter que tenía bastante de especial, pero también de común respeto a los territorios vecinos (Pardo Molero y Ruiz Ibáñez, 2007). Ciertamente, el reino de Murcia contaba con un estatuto diferenciado respecto a otros territorios peninsulares: vistos en el conjunto del Mediterráneo español los dominios murcianos carecían de la singularidad y de la potencia jurisdiccional que tenían el reino de Mallorca, el de Sicilia, el de Valencia o el principado de Cataluña; de la misma forma que carecía de la fuerte unidad interna y de la tan envidiada modernidad defensiva que disfrutaba el reino de Granada (Jiménez Estrella, 2009, pp. 84-89). Junto con este último, Murcia compartía posición dentro de la Corona de Castilla, pero su inclusión relativamente temprana en ella hacía que su definición político-institucional careciera de la coherencia que pudiera tener el antiguo dominio nazarí.

Visto desde la Meseta el reino de Murcia mantenía una mayor homogeneidad. Era uno más de los señoríos que había integrado la Corona de Castilla una vez superado el Macizo Central y, sobre todo, desarticulado el poder almohade. Su peculiar forma de sumisión al infante don Alfonso, en tanto que capitulación en lugar de conquista, implicaba en teoría la sucesión política entre el poder de la última dinastía musulmana, los hudíes, y los reyes castellanos. Pero, más allá de un origen político 
tan curioso, el de Murcia era uno más de los reinos castellanos, un territorio que para el siglo XVI se confundía con el resto de Castilla, así que si hay que buscar similitudes sobre su defensa habrá que buscarlos en los otros dominios castellano-leoneses que se desbordaban más allá de los valles del Duero y el Tajo y que tenían una amplia zona costera o que guardaban frontera con otros reinos cristianos. Al igual que los espacios fronterizos tradicionales (como Galicia, Asturias o la Andalucía Occidental), la defensa del reino de Murcia era el resultado de una superposición poco armónica y poco coherente de viejas instituciones medievales que eran releídas y reapropiadas de forma interesada, tanto por unos poderes locales que estaban en continua competición, cuanto por una monarquía que quería reforzar su posición sobre el territorio sin romper los amplios consensos que la sostenían.

No hay sorpresa en recordar que fue la política activa de los Reyes Católicos la que, como en tantos territorios peninsulares, redefinió la geopolítica regional y la propia organización defensiva del territorio. Hasta ese momento la posición del reino había estado presidida por los frentes terrestres. Al Norte el espacio de la Mancha oriental y central surgía como un ámbito ambiguo donde la gran nobleza y las órdenes militares competían por controlar los pastos y las cañadas ganaderas. Era, sin embargo, el eje Este-Oeste el que había resultado más activo en los siglos tardomedievales. Un reino poco poblado como el de Murcia se veía sacudido por los deseos expansionistas aragoneses que aprovechaban las frecuentes crisis dinásticas castellanas y por las continuas razias nazaríes. Estas últimas no podían amenazar de forma seria la presencia castellana sobre el sureste peninsular, pero no por ello eran menos continuas o molestas, marcando profundamente la memoria de las grandes poblaciones occidentales del reino. Para finales de la edad media quedaba muy lejos el intento del rey Sabio por centrar el esfuerzo marítimo regio en Cartagena y parecía que el gran puerto resultaba indiferente a una política castellana mucho más centrada en su proyección atlántica y meseteña.

La geografía defensiva que sustentaba la situación murciana en el siglo XV cambió radicalmente con la política de Isabel y Fernando. Por un lado, la unión dinástica puso fin a las amenazas procedentes de la Corona de Aragón, por otro, la conquista del reino granadino acabó con la peligrosidad de la frontera oriental del reino. Ambos espacios de peligro siguieron existiendo, más o menos latentes, varias décadas, dado que la beligerancia local podía reactivarse con mucha virulencia. Durante las Germanías el reino de Murcia fue el punto de partida para que las fuerzas virreinales y las propias milicias murcianas ayudaran de forma activa a reprimir la rebelión de sus vecinos $y$, al hacerlo, intentar que se olvidaran las propias veleidades comuneras de las ciudades y la nobleza local (Pardo Molero, 2001, pp. 124-50). Con la insurrección morisca de 1567 las fuerzas disponibles en el reino ayudaron a aplastar la rebelión bajo el mando del marqués de los Vélez y 
de don Juan de Austria (Díaz Serrano, 2009, pp. 394-398; Guerrero Arjona, 2005). El final de la guerra de las Alpujarras terminó por abrir la frontera granadina a la emigración murciana y dejó obsoleto el ya de por sí vetusto sistema defensivo que la cubría. Es significativo que las últimas grandes fortalezas interiores del reino (Mula, Vélez-Blanco) tenían más que ver con el deseo de afirmar el poder de la gran nobleza frente a sus vasallos, que con la competición entre aristócratas o la defensa del reino. La raya de Valencia también se convirtió en un espacio mucho más tranquilo, salvo por la molesta presencia de un bandolerismo más o menos endémico que se beneficiaba de la discontinuidad jurisdiccional o por la alarma de una temida insurrección morisca en 1609, algo que las autoridades murcianas se tomaron muy en serio (Lomas Cortés, 2011, pp. 138-172). Hasta el siglo XVIII se fue articulando una creciente cooperación entre las fuerzas disponibles en Murcia y el sur de Valencia para hacer frente a nuevas y comunes amenazas que ya no venían de la tierra, sino del mar (Pardo Molero y Ruiz Ibáñez, 2007, pp. 436-442; Cózar Gutiérrez y Muñoz Rodríguez, 2008).

Si el eje Este-Oeste perdió su significación geoestratégica grosso modo hasta 1706, otra cosa bien distinta fue el que corría de Norte a Sur. Por un lado, el gobierno de los Reyes Católicos trajo novedades jurisdiccionales decisivas. Las tierras del enorme marquesado de Villena fueron confiscadas a los Pacheco por su apoyo a Juana de Trastámara, quienes, no obstante, siguieron beneficiándose del título (Ortuño Molina, 2003). Por otro, el señorío de Cartagena fue permutado a los Chacón-Fajardo a cambio del marquesado de los Vélez, lo que suponía obtener una excelente salida al mar. La nueva política mediterránea castellana iba a estar basada ahora en una posición mucho más sólida sobre la que se desplegaría una embrionaria administración regia integrada por contador, pagador y veedor, así como por la existencia en la plaza de unas casas reales (Montojo Montojo, 2018). Este proceso fue contemporáneo a la obsolescencia de las castellanías interiores del reino (Murcia, Villena, Chinchilla, Hellín, Lorca...), que bien fueron cayendo en desuso, bien se convirtieron en cargos honoríficos, bien se transmutaron en rentas dadas a sus poseedores.

Para las dos primeras décadas del siglo XVI, el reino parecía convertirse en la puerta de salida de una potencia naval que se estaba consolidando en el Mediterráneo occidental gracias a la tradición aragonesa, a los triunfos de Gonzalo Fernández de Córdoba en Nápoles, a la expansión de los presidios ibéricos en el Norte de África y al protectorado de Carlos V sobre los soberanos musulmanes magrebíes. Pero la posición de vía de salida de los recursos ibéricos iba pronto a complicarse ante la aparición de una nueva amenaza. 


\section{El frente Mediterráneo}

La irrupción en fuerza de los corsarios argelinos, pronto aliados de los otomanos, y los cambios geopolíticos operados en el Norte de África entre los años 1516 y 1574-1578 forjaron una nueva situación para el sureste peninsular (Velasco Hernández, 2019, pp. 154-180). Las poblaciones musulmanas y moriscas podían recuperar la esperanza de un socorro en fuerza de sus correligionarios o de la posibilidad de contar con su ayuda para evacuar la Península. Los presidios españoles y sus aliados se colocaron a la defensiva y los intentos de recuperar la iniciativa o bien fueron limitados, como las expediciones de Túnez en 1534 o 1573, o dieron lugar a fiascos como el de Argel de 1543 o catástrofes como las de Mostaganem o los Gelves. El rosario de puestos que iba de Trípoli al Peñón de Alhucemas se vio reducido de forma dramática primero en el siglo xvi y después, entre el último tercio de la siguiente centuria y 1708, fecha en la que los argelinos ocuparon Orán y Mazalquivir. La presión musulmana no se detuvo en las costas de África. Las potentes escuadras de los corsarios, apoyadas por fuerzas regulares otomanas, se lanzaron con vigor sobre las costas peninsulares. Sus operaciones implicaban desde pequeños navíos a potentes flotas capaces de asaltar localidades costeras medianas. Hoy en día se conoce de forma mucho más precisa la evolución de una amenaza que siendo continua cambió enormemente de amplitud (Lemeunier, 1980, p. 68; Tornel Cobacho y Grandal López, 1987; Velasco Hernández, 2019; Sénéchal, 2020, pp. 170-194). Las décadas que siguieron a 1570 vieron como los argelinos adoptaban naves redondas y cada vez mejor artilladas lo que les permitía confrontar mejor a las fuerzas defensivas ibéricas. A ellos se sumaron para finales del XVI piratas y corsarios norteuropeos que atacaban el tráfico comercial más que los puertos. En fin, en 1640 irrumpió con fuerza una renovada armada francesa que estaría presente ante la misma bocana del puerto de Cartagena en 1643 (Velasco Hernández, 2005), disputando el control de las aguas de Messina a las fuerzas combinadas hispano-holandesas o arrasando el puerto de Alicante en 1691 (Bonnery, 2005).

El binomio paz interior-hegemonía exterior sobre el que se basó el asentamiento del poder Habsburgo en la Península Ibérica era particularmente perceptible en la costa murciana. La pacificación del reino y de sus vecindades trajo una notable prosperidad basada en la explotación de la seda y en la, aún tímida eso sí, roturación de nuevas tierras (Lemeunier, 1998). No obstante, el auge económico que se prolongaría hasta finales de la década de 1620 pese a los consabidos vaivenes, afectó de forma desigual al territorio. El espacio costero siguió infrapoblado por la peligrosidad de las constantes incursiones. Sólo Almazarrón, donde los alumbres atraían a una población estable, y Cartagena lograban fijar a la población. La primera era una pequeña villa 
protegida apenas por un muro y un castillo que se ubicaba varios kilómetros al interior de la marina; la segunda era una mediana ciudad que por su puerto tenía una importancia geopolítica capital para la monarquía (Montojo Montojo, 1993 y 1987), tal y como argumentaban sus vecinos ${ }^{2}$.

Las principales guarniciones de la zona ni siquiera estaban, stricto sensu, en él, sino que protegían las plazas de Orán y Mazalquivir. Estos enclaves debían de garantizar una cierta hegemonía territorial a la presencia española en la zona, facilitar el abastecimiento de trigo y el mantenimiento de una economía estrechamente ligada a la depredación sobre la población local; en términos geopolíticos esta presencia implicaba el bloqueo de cualquier operación de gran envergadura hacia la Península. Como es sabido, las condiciones de vida en los presidios eran miserables y hubo no pocas deserciones. Para sostener la ciudad y la villa se mantenía la carrera de Orán que implicaba a algunas embarcaciones que desde Cartagena y Málaga mantenían el contacto entre ambas orillas (Montojo Montojo y Ruiz Ibáñez, 2009). En el mar se contaba también con las escuadras de galeras y, desde principios del siglo XVII, con embarcaciones que procedían de las Armadas del Océano o que se alquilaban a particulares. Aunque podían usarse de manera puntual para acciones de contracorso y guardacosta ${ }^{3}$, en general se asumía que las flotas reales servían para afrontar ataques de gran envergadura, neutralizarlas en el mar y proteger a los convoyes reales, así que no se podía esperar demasiado de ellas frente a la guerra de baja intensidad que sufrían las costas peninsulares.

En el reino de Murcia, la posición de la administración regia era, siendo muy optimistas, raquítica. No es que no hubiera una voluntad de defender el territorio o una urgencia de hacerlo, es que simplemente no había recursos. Los oficiales reales y su entorno posiblemente no sumarían más de veinte personas en Cartagena. El rimbombante título de teniente general de la artillería ocultaba en realidad a un veterano que había alcanzado un honorable retiro que le permitía gestionar unos pocos cañones que en no pocos casos eran inservibles porque sus cureñas estaban podridas ${ }^{4}$.

2 Un ejemplo entre tantos es el de Pablo Cortés Villarrassa, quien no sólo contribuyó a perseguir a los bandoleros valencianos que asolaban el reino, sino que también había luchado en la guerra de las Alpujarras y servidos dos años con los corsarios españoles y, desde que vivía en Cartagena había servido «en muchos rebatos de moros y emboscadas y emboscadas que sean ofreçido y se halló en tomar y cautibar a Garçia renegado con su galeota con treinta turo y moros cosario [sic] que teya destruyda la costa con muchos robos y cautiberios», Archivo General de Simancas (en adelante AGS), Estado, leg. 1.789, sin número, 29 de julio de 1603, consulta de parte.

Los capitanes cartageneros podían resultar especialmente activos y ambiciosos, como don Luis García de Cáceres que propuso hacer una incursión en Argel para quemar los navíos corsarios durante el ramadán, «la cuaresma de los moros», con tropas procedentes de Granada, una compañía de Cartagena, cuatro fragatas, dos de ellas mallorquinas, y la posible ayuda de la armada inglesa, AGS, Guerra y Marina, leg. 3.917, varios documentos de 1621 y 1622.

4 La limitada artillería de Cartagena se puede verficar en un documento de hacia 1540; AGS, Contaduría Mayor de Cuentas I, sin número: «Rel ${ }^{\mathrm{on}}$ de la artilleria y municiones q tienen las 
Por si fuera poco, su gestión y la de las murallas generaba interminables conflictos de jurisdicción con las autoridades municipales. Dos o tres decenas de soldados famélicos se aburrían en el castillo de Cartagena bajo el mando de unos castellanos que no dejaban de reclamar al gobierno que pagara sus atrasos y les ayudara en sus conflictos. En caso de urgencia siempre se podría recurrir, si había esa suerte, a las tropas estacionadas en las Casas del rey y a las reclutadas en la Meseta o en el reino de Murcia que se reunían para ser enviadas a Italia o África y a las embarcaciones de guerra surtas en la rada del puerto.

La villa de Almazarrón contaría con una pequeña unidad de atajadores a caballo, con suerte poco más de una decena, que resultaría muy eficaz en caso de querer rechazar pequeñas incursiones y vigilar una línea de costa tan despoblada ${ }^{5}$. Aunque no siempre estuvo operativa, en principio debió de pagarse con los ingresos de las torres de defensa o con los derechos que los marqueses de Villena y los Vélez generaban por la explotación económica de la plaza. La presencia de tropas regulares en el reino era algo excepcional, tratándose de unidades de tránsito en dirección a la frontera francesa, portuguesa o hacia Italia. Por parte del rey no había otro socorro disponible que dependiese de su administración directa (Ruiz Ibáñez, 1995, pp. 78-84).

La historiografía se ha volcado tradicionalmente en el estudio de las piedras, algo que parece reforzarse hoy día con la nueva pasión arqueológica que preside las ciencias sociales y la extensión del concepto de patrimonio (Hartog, 2003, pp. 203211). Se conoce de forma más o menos pormenorizada los diversos proyectos que los agentes enviados por la corte hicieron para proteger las costas murcianas. Hay una amplia literatura sobre la evolución de las murallas de Cartagena consolidadas por Carlos V y reforzadas en época de Felipe II, al mismo tiempo que se constata que tales obras siempre quedaron incompletas, que tuvieron un pobre mantenimiento $y$ que se les daba muy poco crédito en caso de un ataque en fuerza, como muestra un informe sobre el estado de las defensas del reino ${ }^{6}$. En esta lógica, una de las especialidades de la historiografía de la defensa del reino de Murcia es el estudio de las torres de defensa de la costa. Esta decena de construcciones en principio tenían una titularidad municipal o nobiliaria. Sin embargo, dentro de la política de uniformización defensiva, de cierre de la costa y de apropiación de los recursos locales dentro de la

cibdades y fortalezas de Cadiz, Gibraltar y Almería, y Cartagena y lo que se les lleva de Málaga a cada una dellas para proveerlas del todo de lo que les falta»; casi un siglo después las cosas no había mejorado mucho: AGS, Guerra y Marina, leg. 923, sin número, 2 de julio de 1625, Cartagena, don Juan de Scarramad a Felipe IV.

5 Quedaría en la memoria la carga que cerca de Almazarrón, y con sus diez jinetes dio don Antonio de Sepúlveda a un desembarco corsario en 1596, desbaratando a más de medio centenar de atacantes; AGS, Guerra y Marina, leg. 459, sin número, 25 de septiembre de 1596, la villa a Felipe II. AGS, Guerra y Marina, leg. 940, sin número: 9 de junio de 1626, el marqués de los Vélez al Felipe IV, informe sobre situación defensiva del reino; y AGS, Cámara de Castilla, Diversos, leg. 26, 30 de septiembre de 1592, Murcia, el corregidor al rey. 
administración regia, la monarquía presionó para lograr que todas ellas, o al menos las más expuestas, pasaran a depender de sus agentes, y completó el sistema con la construcción de otras nuevas entre la década de 1590 y principios del siglo XVII ${ }^{7}$. Se dotó así a esta pieza del sistema defensivo de una cierta unidad que se basaba en unas actividades económicas - pecuarias y pesqueras - que a la vez potenciaba y defendía (Cámara Muñoz, 1990-1991). Las torres daban una mayor seguridad, pero, desde luego, no pusieron fin a las incursiones y en ocasiones las potenciaron al atraer hacia ellas a predadores que sabían que podrían tomar más cautivos si las capturaban. Alejadas de los centros urbanos y distantes de los lugares de socorro, las torres no podían resistir un ataque en forma, así que cuando este se produjo terminaron por caer con sus ocupantes, como sucedió con la torre de Cope en 1602 o con la de Cabo de Palos en 1637 o la de las Águilas en 1697 (Ruiz Ibáñez, 1995, pp. 75-78; Muñoz Rodríguez, 2006). Los torreros sumaban menos de medio centenar de hombres, algo nada impresionante para cubrir los 250 kilómetros de la costa murciana.

¿Era posible la defensa del reino de Murcia cuando las fuerzas reales fijas no alcanzaban, siendo extremadamente optimistas, los cien hombres sobre una población de cien mil habitantes? En realidad, la constatación de entrada es que sí, que efectivamente el reino logró mantener su integridad gracias a formar parte del entramado global defensivo de la monarquía, un entramado que se sostenía con una fiscalidad que experimentó un notable crecimiento entre 1570 y 1590 para dispararse a partir de 1625, desestructurando el modelo productivo, deteriorando las relaciones sociales y acelerando una crisis que resultaría muy violenta para mediados de siglo. El principio de guerra fuera-paz dentro funcionó: no sólo el reino evitó las amenazas mayores, sino que las fuerzas que defendían a la vez patria, reino, tierra y monarquía, fueron capaces de evitar pérdidas catastróficas hasta 1708 con la toma de Orán.

Es cierto que hubo suerte y que, salvo algún intento fallido por tomar Almazarrón (1585), las agresiones contra la costa del reino no buscaron capturar ninguna localidad importante. Pero si se pudo sostener el frente no fue por las fuerzas de la corona, sino porque las de la monarquía incluían a las de las otras instituciones que la conformaban. La compilación de documentos con que se comenzaba este texto muestra la continuidad del hecho decisivo que, para una localidad, en ese caso la propia capital del reino, significaba un estado de guerra casi permanente. No era algo privativo del reino de Murcia y ni siquiera lo era de los territorios mediterráneos. En una parte sustancial de las fronteras de la monarquía, la guerra irregular imponía una situación de alarma que sólo la participación solidaria de las tierras del interior permitía compensar ante la falta de guarniciones profesionales que pudieran responder a la defensa; una forma de defensa que definía a su vez los estatutos políticos de la

7 La contabilidad, y la degradación paulatina del sistema de torres se puede seguir en AMM, leg. 2.734, que incluye una averiguación de 1644 . 
sociedad afectada (Ruiz Ibáñez, 2009; Brunet y Ruiz Ibáñez, 2015; Prak, 2015 y 2018, pp. 140-151).

\section{Un sistema defensivo complejo y en continua evolución}

En teoría el reino de Murcia, y por extensión algunas tierras que iban más allá de sus fronteras hasta penetrar en el centro de la Mancha, se organizaba con una entidad defensiva propia: el adelantamiento. El cargo de adelantado y capitán mayor conllevaba el liderazgo y la coordinación de los recursos defensivos en nombre del rey. Al no tratarse propiamente de una capitanía general sus atribuciones podían quedar difusas o ser cuestionadas con énfasis por las instituciones locales. Los marqueses de los Vélez que tenían el cargo en propiedad hereditaria carecían de una administración permanente, aunque con el tiempo nombraron sargentos mayores (Guillamón Álvarez y Ruiz Ibáñez, 1999, pp. 488-493). Los marqueses o sus tenientes para cuando querían ejercer su autoridad, por ejemplo, ante un socorro a la costa, se veían forzados a nombrar comisarios ad hoc con la esperanza de que las autoridades locales les obedecieran. Su relación con la corte y su posición como principales aristócratas del reino les permitió intentar consolidar una clientela en las diversas localidades (Muñoz Rodríguez, 2004), lo que les resultó útil a la hora de movilizar tropas, por ejemplo, para ayudarles en la expulsión de los judíos de Orán de 1669 (Schaub, 1999, pp. 172179). Para finales de la década de 1610 se calculaba, con radiante e irreal optimismo, que sobre los aproximadamente 30.490 vecinos que se suponía componían el reino se podrían movilizar para socorrer la costa hasta 12.000 hombres $^{8}$. Sin embargo, el poder efectivo de los adelantados dejaba mucho que desear y se veía contestado no sólo por las villas y ciudades, sino también por los justicias regios, sobre todo corregidores y alcaldes mayores, que intentaban liderar por sí mismos las fuerzas de sus distritos (Ruiz Ibáñez, 1995, pp. 141-146). Desde la década de 1630-1640 surgieron nuevos cargos dedicados de forma extraordinaria a la salvaguarda del puerto de Cartagena. Una serie de gobernadores de lo político y lo militar intentaron coordinar la defensa de la plaza, con una titulación que en ocasiones se extendía a la propia ciudad de Murcia (Muñoz Rodríguez, 2003b; Ruiz Ibáñez, 2004, pp. 647-659).

A lo largo del tiempo, y singularmente, en las décadas de 1580 y 1590 , menudearon los planes para estructurar el espacio costero, intentando copiar el modelo granadino mediante la situación de los pagos a unidades móviles sobre los bienes de los moriscos residentes en el reino9. También se insistió, sobre todo en el primer lustro del siglo XVII, en desarrollar un sistema rotativo de permanencia de unidades

8 AGS, Guerra y Marina, leg. 851, sin número, Chinchón, 28 de enero de 1619, don Luis de Navarra a Felipe III.

9 AGS, Guerra y Marina, leg. 286, n 215 al 226, diversas propuestas para reformar la defensa de la costa. 
urbanas en Cartagena para proteger la plaza y para cooperar con las expediciones que se estaban organizando para atacar una vez más Argel (Ruiz Ibáñez, 1995, pp. 89-90). Desechados estos intentos de estructuración militar, quedaba insistir en el sistema de levantamiento clásico de compañías: los rebatos, los socorros y las unidades ciudadanas.

Como en otros territorios europeos y americanos, la base de la defensa era una territorialización del espacio como una unidad defensiva en la que las poblaciones de la retaguardia tenían la obligación de sostener con sus fuerzas armadas a las zonas de frontera. El principio de solidaridad completaba el de autodefensa, dando un sentido de unidad espacial. El distrito resultante incluía las plazas del Norte de África y el adelantamiento de Murcia, un ámbito que por su amplitud participaba con distinta intensidad en la protección de la costa, dado que sus tierras se desbordaban más allá del reino de Murcia, incluyendo distritos del interior de la Mancha (Ruiz Ibáñez, 1995, pp. 85-87). Situadas en primera línea de frente Orán, Cartagena y Almazarrón se defendían por sus propias fuerzas, tanto profesionales como urbanas (Gómez Vizcaíno y Montojo Montojo, 1993). Aunque las tropas del rey, salvo para Orán, no podían vertebrar la defensa, al menos sí podían liderarla. Más en Cartagena que en Almazarrón, aunque en la villa sí había clientes y dependientes del adelantado, los oficiales reales siempre podían reclamar una función directora en la organización de la defensa. Los concejos y los particulares también contribuían a la defensa armando embarcaciones que bien salían a hacer acciones de contracorso, bien salían a correr el Norte de África; estas acciones militares estaban muy ligadas a la élite local cartagenera que así podía sumar el servicio al rey con el beneficio personal. Otra cosa fue el intento de los grandes mercaderes internacionales residentes en la ciudad para que se les diera patente de corso y así justificar el armamento de los navíos con los que participaban en el gran tráfico entre el Mediterráneo y el Atlántico; de ellos destacaría Juan Launnay Longaban de Saint Malo en las décadas de 1610-1620 y, ya para la de 1640, la familia Imperial (Montojo Montojo y Ruiz Ibáñez, 1999, pp. 144-178).

Más al interior, las cosas cambiaban. Las localidades situadas en una franja distante unos 40-70 kilómetros de la costa podían ser llamadas a rebato para reforzar la defensa en caso de amenaza inminente. Este eje geográfico corre de Este a Oeste y une las depresiones del Guadalentín y de la Vega Media del Segura, así como las localidades inmediatamente inmediatas; era la zona más poblada del reino, incluyendo sus dos principales ciudades del interior (Lorca y la propia Murcia) y una serie de villas (Alhama, Mula, Librilla...) sobre las que el marqués de los Vélez podía tener un importante ascendiente. Aquí la densidad de los oficiales regios era mucho menor, circunscribiéndose en tiempos ordinarios al corregidor de ambas localidades, cuya autoridad también se extendía a Cartagena, y a sus exiguos dependientes. La impor- 
tancia del corregimiento de Murcia-Lorca-Cartagena era por lo tanto palmaria a la hora de obedecer o ralentizar las órdenes del adelantado.

A partir de la década de 1590 cuando tras la minoría del III marqués, los Vélez quiso recuperar el control de la defensa basándose en sus propios clientes, se inició un largo conflicto entre ellos y las ciudades que reclamaban conservar la autoridad de la organización militar (Guillamón Álvarez y Ruiz Ibáñez, 1999, pp. 481-482). El triunfo por parte de las ciudades y de sus corregidores en la defensa de su control sobre la organización militar era evidente en la década de 1630 (Ruiz Ibáñez, 1995, pp. 266-286). Este éxito en parte se debía, junto a los siempre fluctuantes equilibrios de poder, a la evidencia de la necesidad de la colaboración urbana en la protección del reino.

Las localidades situadas en la zona de rebato-socorro eran la columna vertebral de la defensa. En ellas también se daba el principio de participación universal de los vecinos en la protección del conjunto del reino. Como consecuencia, el nivel de organización militar de la ciudadanía local era relativamente muy elevado, lo que permitía en caso que se activaran las alarmas, generalmente por sistemas de fogatas, y que tocaran las campanas llamando a las armas, movilizar a una parte importante de la población masculina que ya estaba organizada en compañías. Dependiendo de la envergadura atribuida a la amenaza las ciudades y las villas podían, ipso facto, despachar hacia la costa bien a las unidades más organizadas, bien al conjunto de la fuerza municipal encabezada por la propia bandera de la población y, caso de tenerlo, por el pendón real. Frente a las pocas decenas de hombres que podía llamar el rey, las poblaciones eran capaces de situar un número muchísimo mayor en los puntos sensibles en uno o dos días. Este ámbito era el que más hombres y más rápido podía situar en Cartagena o Almazarrón, pues su capacidad de movilización era muy elevada superando los 1200-1500, un número que, si se debilitó a mediados de siglo ${ }^{10}$, parecería plenamente operativo para finales de la Centuria, como se comprobó en los socorros de 1691 y 1693 (Ruiz Ibáñez, 1995, pp. 89-92; Muñoz Rodríguez, 2003, pp. 150-159). No había discusión de quien tenía el poder, ni tampoco de a quien le correspondía la autoridad, pues las unidades que salían de las poblaciones eran puestas, una vez que estaban extramuros, bajo el mando de la administración regia directa que, además, debía de alimentarlas y sostenerlas pasados tres días.

Más allá de la zona de rebato se extendía un amplio territorio donde el apoyo a la costa tenía un sentido más mediato. La distancia resultaba ya demasiado amplia para poder confiar en que un rebato tuviera un efecto real ante una urgencia. A estas localidades más bien se pedía que bien individualmente, bien agrupándose entre varias, formaran compañías y las despacharan por un tiempo a reforzar las marinas ante

10 Para 1656 hay un intento consciente de la ciudad de Murcia de restaurar, en lo que podía, su organización defensiva, recogido en AMM, Acta Capitular, 1656, ayuntamientos de enero y febrero. 
el temor de una potencial agresión. Generalmente las ciudades de realengo (Villena, Chinchilla) o las grandes villas de Órdenes (Caravaca) podían centralizar estas movilizaciones ${ }^{11}$. Estas demandas de contribución a la protección colectiva del reino, junto con la provincialización propia del desarrollo fiscal de principios del siglo XVII contribuyeron a definir, bien que a regañadientes, una conciencia de pertenencia fiscal a la entidad administrativa común que era el reino de Murcia (Guillamón Álvarez y Ruiz Ibáñez, 1999, pp. 495-497), una conciencia que no eliminaba ni la inclusión en viejas entidades que seguían siendo operativas pese a su menor vitalidad, como el propio marquesado de Villena, ni la posibilidad de que otros servicios le fueran pedidos directamente por la Corona a cada localidad en nombre de la piadosa fidelidad al rey y de la urgente necesidad de la monarquía.

La misma lógica de los socorros mediatos a la costa se extendía a la demanda de refuerzos para proteger la Castilla africana. Las localidades del reino eran llamadas en caso de urgencia para enviar compañías que completaran la dotación del presidio frente a la falta de soldados o ante el crecimiento de la presión argelina. Para los campesinos y artesanos que eran sacados de sus vidas para hacer de soldados por meses o incluso por años en un destino miserable como era la guarnición africana, la experiencia debía de ser angustiosa y desesperante. Sin embargo, esto fue algo ni inusual ni excepcional, dada la debilidad estructural de la posición hispana en el Magreb y la urgencia cotidiana de resistir los ataques otomanos (Ruiz Ibáñez, 1995, pp. 91-92 y 338-345; Muñoz Rodríguez, 2003, pp. 159-166; Blázquez Miguel, 19921993).

Hacia finales del siglo XVI y principios del siglo XVII las formas de contribución individual a la defensa se estaban simplificando dentro de las localidades del reino. Los últimos vestigios de la división por cuantías que había caracterizado a la baja edad media estaban en un proceso de extinción que se consumaría poco antes de 1620 (Centenero de Arce y Díaz Serrano, 2009). Eliminados los caballeros cuantiosos, el cuerpo social quedaba dividido entre quienes prestaban un servicio obligatorio y quienes participaban en él de forma voluntaria. Pecheros e hidalgos servían a la ciudad según su posición estamental, sin que las interesantes propuestas de mediados del siglo XVI hubieran cristalizado de manera operativa en la formación de unidades privilegiadas de tiradores según el modelo flamenco.

Los cambios efectivos no vendrían de los planes que se proponían para racionalizar el uso de los recursos del reino, sino por su capacidad de adaptar las transformaciones globales que reclamaba la Corona. La milicia general establecida en

11 Estas localidades también tenían que ser agradecidas por su servicio dado el escaso control que el adelantado podía tener sobre ellas, como muestra la carta enviada por el marqués de los Vélez a Villena en 1618, elogiando el comportamiento en Cartagena de la compañía del capitán Martín Ochoa enviada por la ciudad a su socorro; Archivo Municipal de Villena, leg. 4, nº 16. 
Castilla como consecuencia de la toma de Cádiz en 1596, tardó apenas una década en ser inoperativa en los territorios interiores de la Península (Thompson,1981, pp. 156163; Jiménez Estrella, 2009, pp. 84-89). No fue así en el reino de Murcia. Las nuevas compañías estaban integradas por vecinos que eran cuidadosamente registrados por los ayuntamientos y que no dejaban de reclamar sus nuevos privilegios. A cambio podían ser movilizados para defender el conjunto de los reinos españoles, y no sólo los castellanos. Surgía así una fuerza mejor entrenada, mejor armada y más disponible para las autoridades regias de las que dependía directamente, pues se consideraba que «están armados y exercitadas como gente vieja» (Ruiz Ibáñez, 1995, p. 257). Aunque fuera limitada en número, en la práctica quizá no más de 450-500 (dos tercios de ellos en la capital), la milicia general pronto se convirtió en un recurso de vanguardia que era mal tolerado por unos ayuntamientos que, por otra parte, no dejaban de ver lo práctico que resultaba contar con una unidad de movilización urgente que, de facto, podía descargarlos en parte de recurrir a la población ordinaria o incluso de levantar compañías ciudadanas pedida ex professo por el rey. Esto no quiere decir que se dejara de llamar a unas fuerzas municipales que habían modernizado de forma notable su propio arsenal entre 1596 y 1600.

Este modelo mixto (fuerzas no profesionales y semiprofesionales) comenzó a deteriorarse rápido en la década de 1630. El surgimiento de las formas de reclutamiento coactivo en nombre del rey, pero gestionada por las villas y generalizadas hacia 1634, introdujo una importante variante en la organización de las relaciones entre súbdito, soberano y poder local. El proceso se complicó aún más con la declaración en 1635 de la guerra por Francia y con las rebeliones de Cataluña y Portugal. De pronto los recursos que pudiera aportar el reino de Murcia no se iban, cuando fueran profesionales, a destinar a las lejanas guerras europeas o, cuando no lo eran, a la defensa del territorio, sino que se exigiría de forma creciente la entrega de hombres para servir en los frentes catalán y extremeño (Ruiz Ibáñez, 2004, pp. 670-678; Montojo Montojo y Maestre de San Juan, 2019).

Las obligaciones del servicio al rey se fueron trasladando, y no sin dificultad, de una vía intermediada por la ciudad, cumplir como ciudadano, a una vía directa, servir como súbdito, por mucho que ésta fuera gestionada por unas autoridades municipales que fungían ahora como reclutadoras de soldados y no sólo como organizadoras de compañías urbanas (Ruiz Ibáñez, 1996). Así, si el servicio a rey se había hecho a través del levantamiento de voluntarios en compañías por conducta (hay identificadas 52 compañías entre 1594 y 1634 con un total aproximado de entre 7.800 y 6.500 hombres), ahora las poblaciones se veían confrontadas a entregar un número determinado de reclutas. Por supuesto, el nuevo sistema se superpuso a lo ya existente, y las compañías urbanas que iban al rebato y socorro de la costa, las que se destinaban a África y las que se enviaban por las villas y ciudades al servicio directo 
del rey siguieron activas a lo largo del medio siglo siguiente, siendo la compañía municipal enviada por la villa de Yecla al frente catalán en 1643 la que dejaría una mayor memoria (Blázquez Miguel, 1983, pp. 33-50).

El resultado de este momento de transición fue un creciente desorden en el que las diversas instancias institucionales y las diversas facciones intentaban beneficiarse de una coyuntura cambiante. El ajuste a la nueva fiscalidad regia fue complejo y se dio a todas las escalas generándose un paulatino deslizamiento de las exigencias militares profesionales hacia los segmentos más jóvenes de la sociedad y reclamando la reserva de los padres de familia para las funciones de defensa local (Ruiz Ibáñez, 2004, pp. 678-686). Dicho en otras palabras: los jóvenes serían más susceptibles de ser enviados a los nuevos tercios provinciales, mientras se intentaría reservar a los cabezas de familia del servicio militar exterior. A través de esta práctica, materializada en el uso de sustitutos y evidente si se compara la evolución de las edades de los reclutados, se lograba disminuir un tanto la tensión creciente en una sociedad asfixiada por las demandas regias.

En este estado de cosas a la desestructuración social que trajo el reclutamiento había que sumar el incremento de la inseguridad interna por uno de sus efectos colaterales: el aumento del bandolerismo. En términos defensivos se constata la aparición de compañías de caballería, algunas de existencia fugaz, que las autoridades públicas usaban para perseguir a las partidas de forajidos, a los prófugos y desertores. El evidente debilitamiento de la posición defensiva del reino fue aún más notable una vez que el territorio se vio diezmado por la terrible peste andaluza de $1647-1648$ y por las catástrofes naturales que les siguieron entre 1651-1653. Sin embargo, se constata que a partir precisamente de ese momento la agresividad de las incursiones norteafricanas en la costa disminuyó un tanto tras haber alcanzado su cenit en las décadas anteriores (Velasco Hernández, 2019, cap. 8). Esto no quiere decir que la peligrosidad disminuyera de forma sustancial, pero sí que los grandes ataques que habían desarticulado el sistema defensivo local dejaron paso a otros de menor escala.

El dilema para los habitantes de las villas y ciudades murcianas se hacía cada vez más insoluble, pues si por un lado reclamar formar parte de las fuerzas locales o incluso de la milicia general era un medio para intentar escapar de la profesionalización mediante el reclutamiento coactivo, por otro lado, sus integrantes se exponían a otros peligros. La milicia general era enviada al frente catalán con relativa frecuencia $(1640,1642$ o 1690) y junto a las fuerzas de composición urbana ordinaria existía el peligro de ser destinados a Orán, lo que podría ser incluso peor como recordaba el memorial citado en el inicio de este texto (Ruiz Ibáñez, 2019, pp. 271-277; Muñoz Rodríguez, 2003, pp. 159-160).

La gran guerra europea pronto se haría presente en las proximidades del reino, cuando la armada francesa comenzara a reforzar su amenaza sobre el sureste penin- 
sular. Esto desarrollaría una nueva forma de solidaridad territorial respecto al reino de Valencia, ahondando un proceso de imbricación entre territorios que superaba en la práctica la división jurisdiccional entre la Corona de Castilla y la de Aragón (Cózar Gutiérrez y Muñoz Rodríguez, 2008). Para ese momento, el reino parecía un tanto recuperado y logró sobrellevar las demandas que la política de Carlos II le exigía; mas esta pedagogía de la guerra pronto sería puesta a prueba.

\section{La defensa de una frontera de guerra}

Hasta comienzos del siglo XVIII, la guerra había sido un factor fundamentalmente exógeno, que obligaba a los vecinos del reino de Murcia a contribuir de manera creciente en la defensa de la costa y de las siempre amenazadas plazas de Orán y Mazalquivir; sin embargo, a partir de 1705, tras la conquista austracista de Barcelona y Valencia, el rápido avance del ejército aliado hacia el sur iba a trasladar la lucha armada hasta las mismas puertas de la capital murciana (Albareda Salvadó, 1993; Torras Ribé, 2001; Pérez Aparicio, 2008). Después de siglos de alejamiento efectivo de la guerra, sus habitantes volvían a experimentar el hecho ya casi olvidado de que la defensa de su tierra estaba unida al auxilio de su monarca, por lo que todos los recursos disponibles se movilizaron: hombres, armas, dinero, víveres, pero también gran número de dispositivos culturales que ayudaban a cohesionar a la sociedad en el objetivo de la resistencia al enemigo.

La Guerra de Sucesión convirtió este reino castellano en una de las principales fronteras peninsulares de la monarquía, cuyo sostenimiento se presentaba esencial para evitar la caída de los reinos andaluces y, con ellos, el sistema de comunicación de las Indias. La amplia colaboración desarrollada entre estos territorios permitió construir una verdadera unión de reinos, referida en diversos lugares como la «liga» o «unión» de «los cinco reynos de las dos Andaluzías» ${ }^{12}$, que salvaba las diferentes jurisdicciones políticas, militares y religiosas a las que pertenecían. Del mismo modo, la proximidad del frente de batalla a los límites regionales generó un creciente desorden político interno, consecuencia de una fractura política que pudo extenderse en distinto grado por el resto de poblaciones castellanas y de la que hasta ahora sólo tenemos algunos indicios (León Sanz y Sánchez Belén, 1998; Muñoz Rodríguez, 2014, pp. 137-170). Este carácter de frontera, que alcanzó una inusitada actividad durante los años 1706 y 1707, implicó una nueva redefinición geopolítica

12 Las expresiones 'liga' o 'unión’ en Archivo Histórico Nacional (en adelante AHN), Estado, leg. 504: Murcia, 24-VII-1706: el obispo Belluga al secretario don José Grimaldo. La inclusión del reino de Murcia en las «dos Andalucías» no se ajustaba a ninguna tradición jurisdiccional y era, más bien, consecuencias de las dramáticas circunstancias. Esta apelación aparece, por ejemplo, en Gazeta general, y especial noticia de los cinco Reynos de las dos Andaluzias, y lo que cada Ciudad vá executando en servicio de [...] FELIPE QVINTO [...], Sevilla: Francisco Garay, 1707 [4 p.]. 
del reino de Murcia y la consolidación de dinámicas políticas que venían gestándose desde décadas atrás.

La falta crónica de soldados profesionales conllevó la militarización de la sociedad murciana a través de un intenso levantamiento de milicias conforme las tropas austracistas alcanzaban los mojones del reino. El 24 de junio de 1706, la ciudad de Cartagena capitulaba ante la armada inglesa del almirante Leack, después de que la flotilla de las galeras de España se sumase al partido del archiduque Carlos cuando se disponía a socorrer las plazas de Orán y Mazalquivir; y unas semanas después el marqués de Rafal proclamaba al candidato austríaco en Orihuela ante el entusiasmo de los habitantes de su gobernación (Muñoz Rodríguez, 2014, pp. 145-147; Pardo y Manuel de Villena, 1910). Frente a estos cambios de lealtades, la capital murciana apenas resistía la tensión generada por el movimiento de tropas en las ciudades cercanas y los planes de entrega que parecían fraguarse en el seno de su dividida élite loca ${ }^{13}$. La organización en milicias de todos sus vecinos hábiles permitiría comprobar la escasa utilidad que para entonces mantenía ya la milicia general, sustituida en la práctica por las unidades parroquiales $\mathrm{y}$, sobre todo, por cuantas compañías crearon ex professo poderosos locales deseosos de hacer patente sus servicios al rey ${ }^{14}$. Regidores de todas las localidades levantaron milicias a cargo de los concejos o a su propia costa, influenciados por la intensa propaganda borbónica que inundaba la sociedad; pero también lo hicieron vecinos acaudalados sin ninguna relación con los grandes concejos, como fue el caso del capitán «don» José Hernández Guerrero, muerto en batalla al frente de una compañía de vecinos de la villa de Espinardo cuando trataba de contener la Cartagena austracista ${ }^{15}$.

Estos cuerpos armados constituyeron el grueso del débil sostén de una capital que sería asediada entre agosto y septiembre de 1706 por las fuerzas aliadas, reforzadas a su vez por un número elevado de soldados no profesionales - el regimiento Alcantarilla - procedentes de la amplia jurisdicción murciana, Cartagena y la Vega Baja del Segura. Si en estas tierras del sureste castellano alcanzó mayor paroxismo los acontecimientos de la guerra, una guerra en gran medida de «paisanos contra paisanos» ${ }^{16}$, fue debido a esa profunda naturaleza civil, ya que, a pesar de la cohesión que se proclamaba, el enfrentamiento armado fracturó familias, corporaciones e instituciones.

13 AHN, Inquisición, leg. 2.846. Murcia, 16-XI-1706: auto del oidor don Juan Riaño.

14 Una parte de estos vecinos en armas engrosarían los cuatro regimientos de milicias ordenados por la Corona. AHN, Estado, leg. 504. Madrid, 13-VI-1706: el secretario Grimaldo a don Daniel Mahoni. Se ofrece un amplio listado de las compañías de milicias levantadas en el apéndice 3 de Muñoz
Rodríguez, 2014. El caso concreto del capitán Hernández está desarrollado en un trabajo de este mismo autor actualmente en prensa.

16 AHN, Estado, leg. 504. Murcia, 17 de agosto de 1706: el obispo Belluga al secretario don José Grimaldo. 
La defensa de la ciudad de Murcia atrajo asimismo a milicias enviadas desde otras localidades del reino, incluso de aquellas escasamente acostumbradas a participar en la protección de la costa frente al peligro berberisco o las velas francesas. El llamamiento efectuado por el obispo Belluga, «capitán general de las tropas» y virrey de Valencia desde julio de 1706, pese a que causaría en un primer momento algunas resistencias entre las autoridades municipales, los corregidores y las propias del adelantamiento - el gobernador de Cartagena como teniente de adelantado- ${ }^{17}$, se demostraría fundamental para el envío de milicianos y recursos monetarios. El título de Belluga no pasaba en absoluto desapercibido, pues representaba un acto de afirmación de Felipe V que modificaba el veto de monarcas anteriores a las pretensiones de los marqueses de los Vélez por consolidar su poder territorial con ese máximo empleo militar.

Mas no fueron los recursos murcianos los únicos en intervenir en el auxilio de la capital. El carácter de «antemural» que desarrolló el espacio murciano favoreció el desplazamiento de milicias procedentes de los reinos andaluces, especialmente de Granada - y en menor medida Jaén, Córdoba y hasta Sevilla—, que además de percibir el peligro más cercano y haber constituido esa «unión de reinos», surgía en gran medida en las relaciones informales establecidas entre Belluga y el presidente de la Chancillería de Granada, don Juan Miguélez de Mendaña, encargado también de la junta de guerra de esa ciudad (Contreras Gay, 2001; Bel Bravo y otros, pp. 142-156, 2002; Muñoz Rodríguez, 2014, pp. 185-187). Tropas a las que habría que añadir los regimientos veteranos enviados por la Corona entrado el otoño de 1706 - especialmente los de Berwick, Mahoni, Ronquillo, los marqueses de Pozo Blanco, Quintana y Santa Cruz-, cuando la estrategia militar permitió rescatarlos de otros frentes peninsulares.

Durante más de dos años el reino de Murcia acaparó un insólito protagonismo entre los múltiples escenarios existentes de la guerra. La introducción de novedades jurisdiccionales fue numerosa, en parte debidas a las urgencias del momento, pero también a la progresiva asunción de espacios de poder que la Corona había logrado durante la centuria anterior. Ese fue el caso de la «comandancia general» (1706), el «tesorero provincial» (1707), los varios «comisarios reales» (1706), el «gobernador militar» de la ciudad de Murcia (1706) o las plazas de «comandante» que se situaron en diversas localidades del reino. El ejercicio de todos estos cargos desde 1706 sirvió de modelo para su establecimiento en los territorios de la Corona de Aragón cuando se conquistasen después de la batalla de Almansa —-25-IV-1707_, además

17 La villa de Almansa planteó un conflicto de jurisdicción cuando el obispo Belluga convocó a las milicias locales, función que le correspondía al adelantado o su teniente. Archivo Casa Medina Sidonia, leg. 2.095. Almansa, 13 de abril de 1706: la villa al duque de Montalto y marqués de los Vélez. 
de configurar la base sobre la que poder introducir reformas administrativas posteriores en el conjunto del espacio peninsular (Giménez López, 2006, pp. 21-228; Iñurritegui Rodríguez, 2008, pp.47-69; Dubet, 2008, pp. 254-268; Dubet y Solbes, 2019, pp. 27-93).

Para un vecino de mediados del siglo XVIII, el adelantamiento constituía desde hacía tiempo una institución anquilosada sin apenas funcionalidad más allá de viejas costumbres representativas, así como un elemento recurrente en la memoria comunitaria, mientras que la intendencia suponía para entonces una realidad tangible en muchos aspectos de su vida cotidiana. Esta impresión no derivaba de una interpretación más o menos subjetiva de la realidad, sino que surgía del reforzamiento de los agentes delegados del monarca durante el conflicto sucesorio, como había sido el nombramiento del «superintendente general de la real Justicia, lo político, guerra y hacienda» en 1712, o del «comandante general de los reinos de Valencia y Murcia», antecedente inmediato de la capitanía general a la que estos dos territorios pertenecerían desde un año después (Andújar Castillo, 2004; y Muñoz Rodríguez, 2010).

\section{Nuevos horizontes tras la guerra}

El enfrentamiento armado dejó un reino aparentemente nuevo. Al terminar la guerra, las cifras de población habían superado las cotas más elevadas del anterior ciclo de crecimiento desarrollado durante el siglo XVI, y nuevos espacios se estaban repoblando y poniendo en producción — en especial, las marinas de las tres grandes ciudades - gracias a la progresiva disminución del peligro berberisco en el litoral mediterráneo a lo largo del setecientos ${ }^{18}$. El intenso comercio que anteriormente se había dirigido hacia las potencias marítimas y sus aliados, ahora se reconducía hacia los puertos franceses, donde arribaban gran cantidad de seda, cereales y plantas de transformación — barrilla — , que, a diferencia de otras épocas, permitieron a los vecinos pensar en el futuro con una mayor confianza. Las bases materiales que se habían puesto desde 1680 no sólo hicieron olvidar los años más críticos de esa centuria, los trágicos años de la «ira de Dios», sino que su impulso se aceleró en las décadas posteriores perfilando una innegable edad de oro que sólo se agotaría en vísperas de la guerra contra Napoleón (Pérez Picazo y Lemeunier, 1984, pp. 132-201; Montojo Montojo, 2008). 1688. AMM, Ayuntamientos Ordinarios, 24 de diciembre de 1688; para la extensa marina lorquina, Archivo Municipal de Lorca (en adelante AML), Acta Capitular, 1689. AML, Ayuntamientos Ordinarios, 23 de julio de 1689. 
Pero el conflicto sucesorio también actuó de catarsis en otros aspectos más relacionados con la manera de percibirse los murcianos. El discurso de lealtad defendido con las armas por una parte importante de la población se convirtió en un modelo para el resto de territorios que componían la monarquía, no pocos de ellos acusados de lesa majestad por haber sostenido la causa del archiduque Carlos. En los años inmediatamente posteriores a la guerra, el origen valenciano, como en una escala regional el proceder de la ciudad de Cartagena, se tomó en los círculos borbónicos más militantes como factores que levantaban cierto recelo por la «traición» que habían cometido contra el legítimo monarca y la poca seguridad en su lealtad que de estas zonas se esperaba ${ }^{19}$. Frente a esa consideración de «sediciosos» en potencia, los murcianos enarbolaban orgullosamente su fidelidad dinástica, lo que servía de justificación para intentar obtener un trato preferente en la prelación de la capital en las nuevas cortes - jura del príncipe Luis_-, modificar la heráldica municipal con el fin de que reflejase esa circunstancia o lograr de la Corona ciertos privilegios en el ámbito local - ferias, retroversión de ventas de jurisdicciones, perdón de deudas- - La experiencia defensiva estaba detrás de estos sentimientos extendidos en la sociedad murciana, reforzados, además, con la llegada de gran cantidad de refugiados filipistas del mismo reino valenciano, los territorios italianos o las ocupadas plazas de Orán y Mazalquivir (Muñoz Rodríguez, 2015). Todo ello hacía que el reino de Murcia se convirtiese en un crisol de la lealtad borbónica y que los discursos más vehementes surgidos en esta frontera - por ejemplo, las cartas pastorales de su obispo-capitán general - alcanzasen amplio eco en otros lugares del orbe hispánico como Nápoles, Lima o México (Muñoz Rodríguez, 2014, p. 109).

No obstante, ese reconocimiento social que se daba a la decidida actuación de gran parte de la sociedad murciana tuvo su mayor apogeo en las gracias otorgadas por el propio soberano. Felipe V regó con mercedes las demostraciones personales más sobresalientes de las élites locales, empleando títulos nobiliarios, hábitos de órdenes militares, hidalguías y diversos nombramientos reales para acreditar el apoyo recibido (Muñoz Rodríguez, 2014, pp. 293-313). Este aumento del capital simbólico de algunos oligarcas murcianos conllevó la ruptura del equilibrio honorífico que se había alcanzado especialmente en la capital murciana, por lo que en la práctica estas nuevas distinciones sirvieron para consolidar los vínculos serviciales con el rey. Es cierto que ya no serían en muchas ocasiones en el espacio regional, devaluado por cuanto volvería a adoptar su condición periférica con la paz, sino en la misma corte o en puestos directamente relacionados con la administración real.

Mientras miles de murcianos ocupaban los confines hasta entonces deshabitados del reino, acrecentando en diversa proporción sus haciendas particulares, otros, 
en un número estimable, colonizaban los resortes administrativos dependientes del monarca. Las secretarías, audiencias y corregimientos peninsulares se convirtieron en las nuevas Indias de aquellos individuos que, a partir de sus servicios directos en la guerra, los de sus parientes o usufructuando la merecida fama de lealtad colectiva, marchaban a continuar sus carreras serviciales (Muñoz Rodríguez, 2014, pp. 320333). Toda una generación de oligarcas filipistas — o sus hijos - consiguieron incorporarse a ese tipo de puestos que ahora se multiplicaban con los decretos de Nueva Planta, consolidando en algunos casos esta dedicación familiar hasta la revolución liberal. El caso murciano de integración política guarda muchas similitudes con la llamada hora navarra (Caro Baroja, 1985 [1969]; Imízcoz Beúnza, 2005), o la no menos notable hora vasca o flamenca (Guerrero Elecalde, 2012; Glesener, 2011), pero quizás todas ellas se engloben en la hora de las provincias que propició Felipe V para gestionar la monarquía tras la guerra a partir de un modelo más autoritario que cercenaba la tradicional autonomía de los reinos y la influencia de la vieja nobleza. Una hora en la que el requisito indispensable venía dado por los timbres de honor que proporcionaban las diversas formas de participación que se pudieron presentar durante el conflicto sucesorio.

Junto a ese espacio de expansión que representaba la administración territorial, hasta entonces muy limitado, el Mediterráneo italiano se configuraría como el otro eje de atracción de los vecinos del reino de Murcia. Sin embargo, esta vinculación con Sicilia, Parma o Nápoles, que volverían a situarse en la estela de la monarquía entre las décadas de 1720 y 1730, se debió a un reflejo de las prioridades marcadas por la nueva dinastía en sus deseos de resurgir su influencia en Italia (Storrs, 2016, pp. 182-200). La posición destacada lograda por algunos individuos originarios del reino, que integraban la Armada de Felipe V, se vio reconocida, incluso, con títulos nobiliarios concedidos por el nuevo rey de las Dos Sicilias, el infante don Carlos de Borbón: el jefe de la escuadra del Mediterráneo don Donato Domas, marqués del Bloqueo (1736); o los capitanes de galeras don Felipe de Borja, marqués de Camachos (1736), don Juan Ambrosio García de Cáceres, marqués de Cáceres (1736) o don José Antonio Rato, marqués de Campo Nubla (1736), entre otros (Maestre de San Juan-Pelegrín, 2011).

Estos títulos nobiliarios, además de acrecentar la inflación de mercedes que se experimentó durante el Setecientos, reflejaba el papel protagonista que la Corona reservaba al puerto de Cartagena en el Mediterráneo. Como los Reyes Católicos a comienzos del siglo XVI, Felipe V convirtió a este puerto en la base de su proyección mediterránea, esta vez dirigida fundamentalmente a los territorios italianos perdidos en Utrecht. En Cartagena residió la sede del departamento marítimo (1726), además de crearse poco después un arsenal (1732), dos proyectos fundamentales de la Corona por ordenar las necesidades defensivas de las costas peninsulares (Pérez-Crespo 
Muñoz, 1992). Al mismo tiempo, estas iniciativas cortesanas, junto a un refuerzo de las fortificaciones locales, la intensificación del corsarismo contra potenciales enemigos y, sobre todo, al aumento de la población litoral, contribuyeron al progresivo descenso del peligro berberisco, que pasó de ser un temible elemento estructural a un recuerdo cada vez más lejano en la memoria.

Qué lejos quedaban ya los tiempos en los que la defensa de la costa murciana y las plazas de Orán y Mazalquivir suponían plataformas adecuadas para desarrollar servicios retribuibles por la Corona $^{20}$; o incluso constituían una parte fundamental del comercio mediterráneo de cereales y, sobre todo, esclavos, que hacían de Cartagena, junto a Málaga, una de sus puertas de entrada a España (Vincent, 2003). La caída de estos enclaves, además de la aparición de otras áreas alternativas, hizo virar en parte los intereses tradicionales de los murcianos en el norte de África: la prueba más evidente es que la empresa de la reconquista de Orán apenas tuvo trascendencia en el puerto de Cartagena, se gestionó desde la capitanía general de Valencia —el príncipe de Campo Florido - y estuvo liderada por un aristócrata ajeno al ámbito murciano, el conde de Montemar — don José Carrillo Albornoz-, cuya flota partió del floreciente puerto de Alicante en 1732 para acabar con el dominio argelino allí establecido desde 1708 (Fé Cantó, 2016). Pero si la influencia murciana en las plazas norteafricanas no volvería seguramente a restablecerse en los niveles que habían alcanzado durante doscientos años atrás, el Mediterráneo recuperaría de nuevo el papel que había tenido como ámbito natural de expansión de los vecinos del reino de Murcia.

\section{Conclusiones}

En su percepción de la guerra en la edad moderna la población del reino de Murcia acumuló múltiples experiencias procedentes de la respuesta a diversas amenazas que no fueron ni constantes, ni unidireccionales. El espacio murciano se definió y redefinió a través de las necesidades que implicaba que fuera la frontera Sur o las fronteras meridianas, a Poniente y Levante, los focos principales de inseguridad. La consolidación de una identidad tan difusa como fuertemente castellana, pese al origen plural de su población, se ahondó lógicamente por la ausencia de discontinuidades

20 Esos fueron los casos, entre tantos otros, del regidor de Cartagena, don Alonso Hernández Reillo, que levantó una compañía de 150 hombres para el socorro de esta plaza; o de los tres regidores lorquinos, don Alonso de Guevara, don Pedro de Tudela y don Diego de Alburquerque, que enviaron tres compañías con doscientos hombres en total a la defensa de Orán de 1685. Estas actuaciones les supondrían alcanzar un hábito de orden militar a cada uno: AGS, Guerra $y$ Marina, 2.789, sin número. Cartagena, 13 de septiembre de 1688: don Antonio de Heredia Bazán, gobernador, al secretario del consejo de Guerra don Juan Antonio López de Zárate.; y 2.882, sin número. Cartagena, 6 de agosto de 1691: los mismos; dos años más tarde sucedería lo mismo con el también regidor de Cartagena don Simón García Angosto, 2.942, sin número: Cartagena, 11 de agosto de 1693: los mismos. 
bélicas entre los territorios murcianos y toledanos de La Mancha. Esta jurisdicción se territorializó a partir de complejos juegos de poder en los que también se incluía definir el papel jugado por sus habitantes en la defensa de su tierra y del Imperio del que formaban parte. En ese proceso, las transformaciones que en la gestión de la guerra y de la participación en la defensa trajeron las necesidades de la monarquía fueron contundentes. Los murcianos, desde la costa a los corregimientos de Villena o Chinchilla, fueron llamados cada vez más en el siglo XVII a servir por obligación en las fuerzas reales; mientras que el servicio indirecto a través de las instituciones tradicionales persistía, aunque se fuese haciendo cada vez más complementario. La ruptura de la separación de los ámbitos y tipos de participación en la defensa regional y en la defensa imperial, y la confusión de ambos, fue un claro signo del desarrollo de la autoridad real en un poder cada vez más efectivo, aunque éste tardara en expresarse en una administración directa más o menos coherente. Para eso haría falta una guerra local y a gran escala, un conflicto en el que, si se ahondaron y sistematizaron tales tendencias, paradójicamente, la perseverancia de las fuerzas y el espíritu republicano de las ciudades y villas murcianas habría de ser decisivo.

\section{AGRADECIMIENTOS}

Este artículo está realizado en el marco del proyecto de investigación «Hispanofilia IV: Los mundos ibéricos frente a las oportunidades de proyección exterior y a sus dinámicas interiores», HAR2017-82791-C2-1-P, Ministerio de Ciencia, Innovación y Universidades-FEDER. La edición de este trabajo ha sido posible gracias a la ayuda del Programa de Grupos de Potencial Crecemento concedida por la Consellería de Cultura, Educación e Universidade da Xunta de Galicia al GI-1921 de la USC (Referencia: GPC, ED 431B 2021/06). 


\section{Bibliografía}

Albareda Salvadó, Joaquim (1993), Els catalans i Felip $V$, de la conspiració a la revolta (1700-1705), Barcelona, Vicens Vives.

AndúJar CASTIllo, Francisco (2004), «Capitanes generales y capitanías generales en el siglo XVIII», Revista de Historia Moderna, 22, pp. 291-320.

Bel Bravo, María Antonia, y otros (2002), La Guerra de Sucesión en la Provincia de Jaén desde la perspectiva de la nueva historia cultural, Jaén, Universidad. $<$ https://doi.org/10.14198/pasado2004.3.15-17>.

Blázquez Miguel, Juan (1983), El capitán Martín Soriano Zaplana, Yecla, Ayuntamiento.

Blázquez Miguel, Juan (1992-1993), «Aportación yeclana a la defensa de las costas en el siglo XVII. Milicianos y bandoleros», Yakka. Revista de Estudios yeclanos, 4, pp. 41-48.

BRunet, Serge y Ruiz IbáÑEz, José Javier (dirs.) (2015), Les milices dans la première modernité, Rennes, Presses Universitarires de Rennes-Red Columnaria. $<$ https://doi.org/10.4000/books.pur.94027>.

CÁmara Muñoz, Alicia (1990 y 1991), «Las torres del litoral en el reinado de Felipe II: Una arquitectura para la defensa del territorio», Espacio, tiempo y forma. Serie VII, Historia del Arte, 3 y 4, pp. 55-86 y 53-94.

CARo Baroja, Julio (1985), La hora Navarra del XVIII (personas, familias, negocios e ideas), Pamplona, Comunidad Foral de Navarra [1969].

Centenero de Arce, Domingo (2011), De repúblicas urbanas a ciudades nobles. Un análisis de la evolución y desarrollo del republicanismo castellano (15501621), Madrid, Biblioteca Nueva.

Centenero de Arce, Domingo y Díaz Serrano, Ana (2009), «La reconstrucción de una identidad hidalga: caballeros de cuantía de la ciudad de Murcia durante los siglos XVI y XVII», en Soria Mesa, Enrique, Bravo Caro, Juan Jesús, y Delgado Barrado y José Miguel (eds.), Las élites en la época moderna: la monarquía española, Córdoba, Universidad, pp. 95-106.

Contreras Gay, José (2001), «La unión defensiva de los reinos de Andalucía en la Guerra de Sucesión», en Castañeda Delgado, Paulino y Gómez Piñol, Emilio (coords.), La Guerra de Sucesión en España y América, Madrid, Ministerio de Defensa, pp. 15-78.

Cózar Gutiérrez, Ramón y MuÑoz Rodríguez, Julio David (2008), «Monarquía, poder y movilización social en tiempos de crisis. La población del reino de 
Murcia en los socorros de Alicante y Cartagena de 1691», Ensayos: Revista de la Facultad de Educación de Albacete, 23, pp. 65-102.

Díaz Serrano, Ana (2009), «Repúblicas movilizadas al servicio del rey. La Guerra del Mixtón y el Levantamiento de las Alpujarras desde una perspectiva comparada», en Ruiz Ibáñez, José Javier (coord.), Las milicias del rey de España. Sociedad, política e identidad en las Monarquías Ibéricas, Madrid, Fondo de Cultura Económica y Red Columnaria, pp. 378-403.

Dubet, Anne (2008), Un estadista francés en la España de los Borbones. Juan Orry y las primeras reformas de Felipe V (1701-1706), Madrid, Biblioteca Nueva.

Dubet, Anne y Solbes Ferri, Sergio (2019), El rey, el ministro y el tesorero. El gobierno de la Real Hacienda en el siglo XVIII español, Madrid, Marcial Pons. $<\mathrm{https}$ ://doi.org/10.33231/j.ihe.2020.01.007>.

FÉ CANTó, Luis Fernando (2016), «El desembarco en Orán en 1732. Aproximación analítica a una operación compleja», Revista Universitaria Historia Moderna, 5/10, pp. 89-110.

García Moreno, Sabina (2014), «La defensa de la costa mazarronera a finales del reinado de Felipe II», en Martínez Alcalde, María y Ruiz Ibáñez, José Javier (eds.), Felipe II y Almazarrón: La construcción global de un Imperio local. Vivir, defender y sentir la frontera, Murcia, Editum, pp. 277-292.

GiméNEZ LóPEZ, Enrique (2006), Los servidores del rey en la Valencia del siglo XVIII, Valencia, Istitutió Alfons el Magnánim.

Gómez Vizcaino, Aureliano y Montojo Montojo, Vicente (1993), «El elemento humano en la defensa de Cartagena durante el siglo XVI y principios del XVII», en Cruces Blanco, Esther (coord.), La Organización Militar en los siglos XV y XVI (II Jornadas Nacionales de Historia Militar), Málaga, Cátedra General Castaños, Universidad de Cádiz, pp. 317-328.

Guerrero ArJona, Melchor (2005), Lorca, de ciudad de frontera a ciudad moderna: transformaciones políticas, sociales y económicas (1550-1598), Murcia, Real Academia Alfonso X el Sabio.

GuERRERo ElECALDE, Rafael (2012), Las élites vascas y navarras en el gobierno de la monarquía borbónica: redes sociales, carreras y hegemonía en el siglo XVIII (1700-1746), Bilbao, Universidad del País Vasco.

Glesener, Thomas (2011), «La hora felipista del siglo XVIII. Auge y ocaso de la nación flamenca en el ejército borbónico», Cuadernos de Historia Moderna. Anejos, 10, pp. 77-101.<https://doi.org/10.5209/rev_CHMO.2011.38671>.

Guillamón Álvarez, Francisco Javier, y MuÑoz Rodríguez, Julio David (2007), «Las milicias de Felipe V: la militarización de la sociedad castellana durante la Gue- 
rra de Sucesión», Revista de historia moderna: Anales de la Universidad de Alicante, 25, pp. 89-112. <https://doi.org/10.14198/RHM2007.25.03>.

Hartog, François (2012) Régimes d'Historicité. Présentisme et expériences du temps, París, Séuil [2003].

Imízcoz BeunZA, José María (2005), «La hora navarra del XVIII: relaciones familiares entre la Monarquía y la aldea», en Juan de Goyeneche y el triunfo de los navarros en la Monarquía Hispánica del siglo XVIII, Pamplona, E.U.N.S.A., pp. 45-78.

IÑurritegui Rodríguez, José María (2008), Gobernar la ocasión. Preludio político de la Nueva Planta de 1707, Madrid, Centro de Estudios Políticos y Constitucionales.

JimÉNEZ Estrella, Antonio (2009), «Las milicias en Castilla: evolución y proyección social de un modelo de defensa alternativo al ejército de los Austrias», en Ruiz Ibáñez, José Javier (coord.), Las milicias del rey de España. Sociedad, política e identidad en las Monarquías Ibéricas, Madrid, Fondo de Cultura Económica y Red Columnaria, pp. 72-103.

Lemeunier, Guy; Munuera Rico, Domingo y Muñoz Barberán, Manuel (1980), «Economía y sociedad murciana en el tránsito de un siglo a otro», Historia de la Región de Murcia, Murcia, Ediciones Mediterráneo, vol. 6.

LEMEUNIER, Guy (1999), «Señores, oligarcas y campesinos: la construcción del espacio agrario murciano en el siglo XVI», en Belenguer Cebrià, Ernest (coord.), Felipe II y el Mediterráneo, Barcelona, Sociedad Estatal para la Conmemoración de los Centenarios de Felipe II y Carlos V, vol. 1, pp. 167-178.

León Sanz, Virginia y Sánchez Belén, Juan Antonio (1998), «Confiscación de bienes y represión borbónica en la Corona de Castilla a comienzos del siglo XVIII», Cuadernos de Historia Moderna, 21, pp. 127-175.

LOMAs CORTÉs Manuel (2011), El proceso de expulsion de los moricos de España (1609-1614), Valencia, Universitat de Valencia-Universidad de Granada-Universidad de Zaragoza.

Maestre de San Juan-Pelegrín, Federico (2011), «La aristocracia de Cartagena en el siglo XVIII», Murgetana, 125, pp. 103-126.

Montojo Montojo, Vicente (1987), Cartagena en la época de Carlos V: crecimiento demográfico y conflictividad social, transformaciones económicas, Murcia, Real Academia Alfonso X el Sabio.

Montojo Montojo, Vicente (1993), El siglo de oro en Cartagena (1480-1640): evolución económica y social de una ciudad portuaria del sureste español y su comarca, Cartagena, Real Academia Alfonso X el Sabio. 
Montojo Montojo, Vicente y Ruiz IbáÑEz, José Javier (1998), Entre el lucro y la defensa.

Las relaciones entre la Monarquía y la sociedad mercantil cartagenera. Comerciantes y corsarios en el siglo XVII, Murcia, Real Academia Alfonso X el Sabio.

Montojo Montojo, Vicente (2008), «Los comerciantes de Alicante y Cartagena en la Guerra de Sucesión», Estudis, 34, pp. 219-239.

Montojo Montojo, Vicente y Maestre de San Juan, Federico (2019), «Cartagena y la Guerra de Restauración Portuguesa (1640-1668)», Revista de estudios extremeños, 75-22, pp. 381-404.

Montojo Montojo, Vicente y Ruiz IbÁÑEz, José Javier (2009), «Relaciones y agentes comerciales entre Orán y el Reino de Murcia en la primera mitad del siglo XVII», Murgetana, 120, pp. 111-127.

MuÑoz Rodríguez, Julio David (2003), Damus ut des: los servicios de la ciudad de Murcia a la Corona a finales del siglo XVII, Murcia, Real Academia Alfonso $\mathrm{X}$ el Sabio.

MuÑoz RodRíguez, Julio David (2003b), «El gobernador de lo político y militar: Aparición y consolidación de una nueva figura administrativa en la defensa de las costas del Mediterráneo meridional (ss. XVII-XVIII)», Tercer Congreso de Historia de Andalucía, Córdoba, pp. 191-202.

MuÑoz Rodríguez, Julio David (2004), «Servir a los Fajardo. Una geografía del poder clientelar en el reino de Murcia (ss. XVI-XVIII)», en Guillamón Álvarez, Francisco Javier, Muñoz Rodríguez, Julio D., Sabatini, Gaetano y Centenero de Arce, Domingo (eds.), Gli Eroi Fassardi. Movilización social y memoria política en el reino de Murcia (ss. XVI-XVIII), Murcia, pp. 32-64.

MuÑoz Rodríguez, Julio David (2006), «Torres sin defensa, defensa sin torres. Las fortificaciones en el resguardo de la costa murciana a finales del siglo XVII», Actas de las V Jornadas sobre fortificaciones, piratería y corsarismo en el Mediterráneo, Murcia, Aforca-Ayuntamiento de Cartagena, pp. 133-151.

MuÑoz RodríGuez, Julio David (2010), «El superintendente austriaco y el intendente borbónico. La evolución de un modelo de gestión de los recursos fiscales en la Monarquía hispánica», en Dubet, Anne y Ruiz Ibáñez, José Javier (eds.), Las monarquías española y francesa (siglos XVI-XVIII): ¿dos modelos políticos?, Madrid, Casa de Velázquez, pp. 131-144.

MuÑoz Rodríguez, Julio David (2014), La séptima corona. El Reino de Murcia y la construcción de la lealtad castellana en la Guerra de Sucesión (1680-1725), Murcia, Editum.

ORtuÑo Molina, Jorge (2003), La incorporación del marquesado de Villena a la Corona de Castilla en el reinado de los Reyes Católicos, Murcia, Universidad. 
Pardo y Manuel de Villena, Alfonso (1910), El marqués de Rafal y el levantamiento de Orihuela en la Guerra de Sucesión (1706), Madrid, Jaime Ratés Editor.

Pardo Molero, Juan Francisco (2001), La defensa del imperio. Carlos V, Valencia y el Mediterráneo, Madrid, Sociedad Estatal para la Conmemoración de los Centenarios de Carlos Quinto y Felipe II.

Pardo Molero, Juan Francisco y Ruiz IbáÑEz, José Javier (2007), «Una Monarquía, dos reinos y un mar. La defensa de los reinos de Valencia y Murcia en los siglos XVI y XVII», en Cancila, Rosela (a cura de), Mediterraneo in armi (secc. $X V$-XVIII), Palermo, Mediterranea, tomo 2, pp. 429-466.

Pérez Picazo, María Teresa y Lemeunier, Guy (1984), El proceso de modernización en la Región Murciana (siglos XVI-XX), Murcia, Editora Regional. <https:// doi.org/10.1017/s0212610900014786>.

PRAK, Maarten (2015), «Citizens, soldiers and civic militias in Late Medieval and Early Modern Europe», Past \& Present, 228, pp. 93-125. <https://doi. org/10.1093/pastj/gtv030>.

PRAK, Maarten (2018), Citizens without Nations. Urban citizenship in Europe and the World c.1000-1789, Cambridge, Cambridge University Press. $<$ https://doi. org/10.1017/9781316219027>.

Pérez Aparicio, Carme (2008), Canvi dinastic i Guerra de Successió. La fi del Regne de València, Valencia, Edicions 3 i 4, 2 vols.

Pérez-Crespo Muñoz, María Teresa (1992), El arsenal de Cartagena en el siglo XVIII, Madrid, Editorial Naval.

Ruiz IBÁÑEz, José Javier (1995), Las dos caras de Jano. Monarquía, ciudad e individuo. Murcia, 1588-1648, Murcia, Universidad.

Ruiz IBÁÑEZ, José Javier (1996), «Sujets et citoyens: les relations entre l’Etat, la ville, la bourgeoisie et les institutions militaires municipales à Murcie (XVIe-XVIIe siècle)», en Boone, Marc y Prak, Maarten (eds.), Status individuels, status corporatifs et status judiciaires dans les villes européennes (moyen âge et temps modernes/ Individual, corporate and judicial status in European cities (late middle ages and early modern period, Lovaina, Garant, pp. 129-156.

RuIz IBÁÑEZ, José Javier (2004), «Tiempo de guerra, tiempo de cambio. Resistencias, realidades y representaciones en los comienzos de la transición al pleno absolutismo en el reino de Murcia (1642-1669)», en Rizzo, Mario, Ruiz Ibáñez, José Javier y Sabatini, Gaetano (eds.), Le Forze del principe. Recursos, instrumentos y límites en la práctica del poder soberano en los territorios de la Monarquía Hispánica, Murcia, Universidad, 2004, vol. 2, pp. 633-696. 
RuIz IbÁÑEz, José Javier (coord.) (2009), Las milicias del rey de España. Sociedad, política e identidad en las Monarquías Ibéricas, Madrid, Fondo de Cultura Económica y Red Columnaria.

RuIz IbÁÑEZ, José Javier (2019), «El final de un sueño imperial: guerra y poder en Castilla tras 1635», Studia Historica., Historia Moderna, 41, 1, pp. 259-288. $<$ https://doi.org/10.14201/shhmo2019411259288>.

Schaub, Jean Frédéric (1999), Les juifs du roi d'Espagne. Oran, 1509-1669, París, Hachette.

SÉNÉCHAL, Antoine (2020), Par-delà le déclin et l'échec, une histoire aux confins de la Monarchie Hispanique. Le préside d'Oran et de Mersel-Kébir des années 1670 aux années 1700, Ecole des Hautes Études en Sciences Sociales [Tesis doctoral inédita].

Storrs, Christoper (2016), The Spanish Resurgence, 1713-1748, New Haven, Universidad de Yale.

Thompson, Irving Anthony A. (1981), Guerra y Decadencia. Gobierno y administración en la España de los Austrias, 1560-1620, Barcelona, Crítica.

Tornel Cobacho, Cayetano y Grandal López, Alfonso (1987), «El peligro de las grandes flotas y la defensa de Cartagena entre 1580 y 1630», en VV.AA., Homenaje al profesor Juan Torres Fontes, Murcia, Real Academia Alfonso X, pp. 1657-1671.

Torras Ribé, Josep Maria (2001), La Guerra de Successió i els Sitges de Barcelona (1697-1714), Barcelona, Rafael Dalmau Editor.

Velasco Hernández, Francisco (2014), «La defensa de la costa de Lorca y Mazarrón en el siglo XVI», Martínez Alcalde, María y Ruiz Ibáñez, José Javier (eds.), Felipe II y Almazarrón: La construcción global de un Imperio local. Vivir, defender y sentir la frontera, Murcia, Editum, pp. 235-248.

Velasco Hernández, Francisco (2005), El otro Rocroi: la guerra naval contra Felipe IV en el Mediterráneo suroccidental (o Mancha Mediterránea), Cartagena, Editorial Aglaya.

Velasco Hernández, Francisco (2019), Corsarismo, piratería y guerra costera en el sureste español. El acoso turco berberisco a las costas de Alicante, Murcia y Almeria en los siglos XVI y XVII, Cartagena, Nova Espartaria.

VINCENT, Bernard (2003), «Juifs et esclavage à Oran», García Arenal, Mercedes (ed.), Entre el Islam y Occidente, los judios magrebies en la Edad Moderna, Madrid, Casa de Velázquez, pp. 245-252. 